\title{
Adsorption of hydroxamate siderophores and EDTA on goethite in the presence of the surfactant sodium dodecyl sulfate Naraya Carrasco ${ }^{1}$, Ruben Kretzschmar*1, Jide $\mathrm{Xu}^{2}$ and Stephan M Kraemer ${ }^{1,3}$
}

\begin{abstract}
Address: ${ }^{1}$ Institute of Biogeochemistry and Pollutant Dynamics, Department of Environmental Sciences, ETH Zurich, CHN, CH-8092 Zurich, Switzerland, ${ }^{2}$ Chemistry Department, University of California, Berkeley, California, 94720-1460, USA and ${ }^{3}$ Department of Environmental Geosciences, University of Vienna, Althanstrasse 14, A-1090 Vienna, Austria
\end{abstract}

Email: Naraya Carrasco - naraya.carrasco@gmail.com; Ruben Kretzschmar* - kretzschmar@env.ethz.ch; Jide Xu - jide@berkeley.edu; Stephan M Kraemer - stephan.kraemer@univie.ac.at

* Corresponding author

Published: 13 June 2009

Geochemical Transactions 2009, 10:5 doi:10.1186/1467-4866-10-5
Received: 3 September 2008

Accepted: 13 June 2009

This article is available from: http://www.geochemicaltransactions.com/content/lo/l/5

(C) 2009 Carrasco et al; licensee BioMed Central Ltd.

This is an Open Access article distributed under the terms of the Creative Commons Attribution License (http://creativecommons.org/licenses/by/2.0), which permits unrestricted use, distribution, and reproduction in any medium, provided the original work is properly cited.

\begin{abstract}
Siderophore-promoted iron acquisition by microorganisms usually occurs in the presence of other organic molecules, including biosurfactants. We have investigated the influence of the anionic surfactant sodium dodecyl sulfate (SDS) on the adsorption of the siderophores DFOB (cationic) and DFOD (neutral) and the ligand EDTA (anionic) onto goethite $(\alpha-\mathrm{FeOOH})$ at $\mathrm{pH} 6$. We also studied the adsorption of the corresponding I:I Fe(III)-ligand complexes, which are products of the dissolution process. Adsorption of the two free siderophores increased in a similar fashion with increasing SDS concentration, despite their difference in molecule charge. In contrast, SDS had little effect on the adsorption of EDTA. Adsorption of the Fe-DFOB and Fe-DFOD complexes also increased with increasing SDS concentrations, while adsorption of Fe-EDTA decreased. Our results suggest that hydrophobic interactions between adsorbed surfactants and siderophores are more important than electrostatic interactions. However, for strongly hydrophilic molecules, such as EDTA and its iron complex, the influence of SDS on their adsorption seems to depend on their tendency to form inner-sphere or outer-sphere surface complexes. Our results demonstrate that surfactants have a strong influence on the adsorption of siderophores to Fe oxides, which has important implications for siderophore-promoted dissolution of iron oxides and biological iron acquisition.
\end{abstract}

\section{Introduction}

The bioavailability of $\mathrm{Fe}(\mathrm{III})$ in oxic soils, sediments, and surface waters at near-neutral $\mathrm{pH}$ is limited by the low solubility and slow dissolution rates of iron oxides and hydroxides. In order to overcome this low iron solubility, many microorganisms and roots of graminaceous plants exude highly $\mathrm{Fe}(\mathrm{III})$-specific, low-molecular weight $(0.5$ to $1.5 \mathrm{kDa}$ ) ligands, the a group of compounds called siderophores [1-5]. Hundreds of structurally distinct siderophores are known, typically with ligating catecholate, carboxylate, $\alpha$-hydroxycarboxylate, or hydroxamate functional groups $[2,6]$. Most siderophores are hexadentate and form 1:1 Fe(III)-complexes [7-10]. Desferrioxamine-B (DFOB), presented in Figure 1, is an example of a cationic $(\mathrm{pH}<8)$ trihydroxamate siderophore found in both terrestrial and marine systems [11]. Sub-micromolar siderophore concentrations have been observed in soil solutions [12]. The role of siderophores in enhancing the bioavailability of iron depends on its specificity for iron. For example, even in soils in equilibrium with calcium carbonate, where otherwise strong competition between $\mathrm{Ca}$ and iron for complexation would be expected, the 

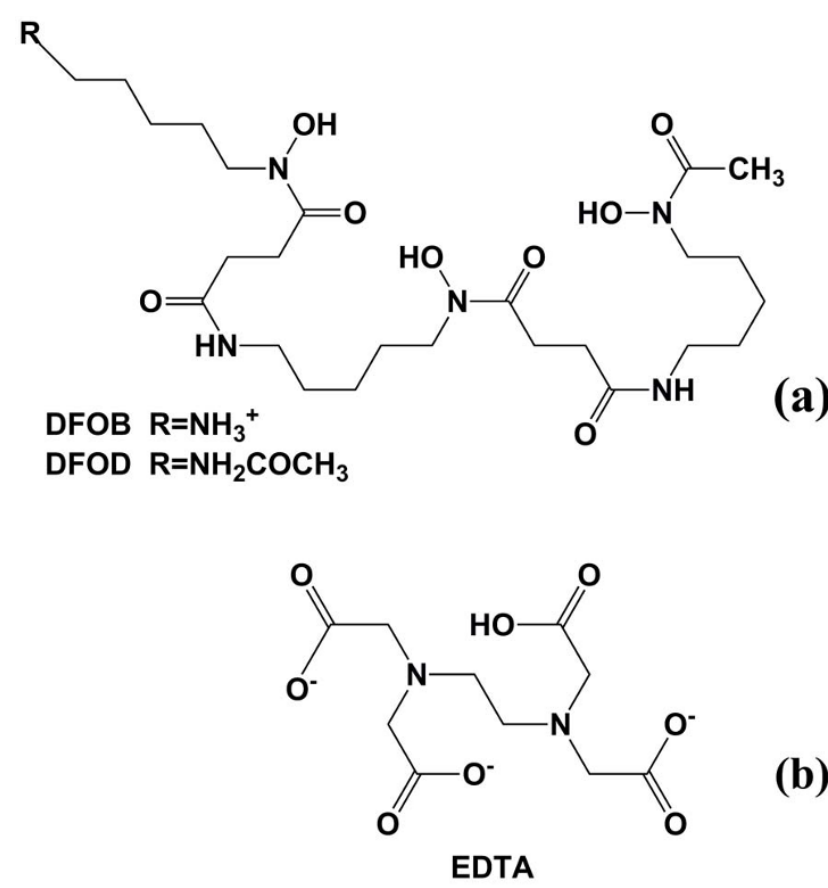

(b)

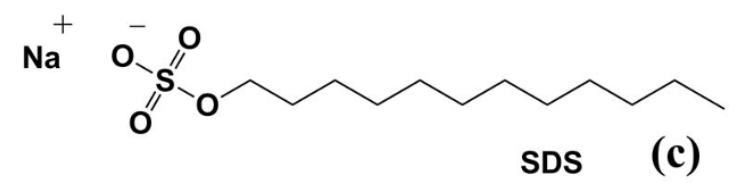

\section{Figure I}

(a) Structure of the siderophores desferrioxamine-B (DFOB) and desferrioxamine-D (DFOD). The terminating group $\mathrm{R}$ of DFOB is an amine group with a $\mathrm{pK}_{\mathrm{a}}$ of 8.4. The three hydroxyl groups have $\mathrm{pK}_{\mathrm{a}}$ values of $8.73,8.99$, and 10.1 , respectively [II]. The terminating group $R$ of DFOD is acetylated and has no charge. The stability constant for FeDFOB and Fe-DFOD are $10^{30.7}$ and $10^{30.76}$, respectively $(\mathrm{I}=0 . \mathrm{IM})$ [7]. (b) Structure of EDTA with $\mathrm{pK}_{\mathrm{a}}$ values of 2 , $2.69,6.13$, and $9.52[3 \mathrm{I}]$. The dominant species under the experimental conditions is doubly negatively charged. (c) Structure of the sodium salt of the anionic surfactant dodecyl sulfate (SDS) with a $\mathrm{pK}_{\mathrm{a}}$ of 2.3 [22].

dominant soluble species of the iron specific DFOB is the free, fully protonated ligand.

An important function of siderophores in biological iron acquisition is the acceleration of iron oxide dissolution [13]. Organic ligands and their complexes can adsorb onto iron oxides by forming inner-sphere and/or outersphere surface complexes. For simplicity, the term "outersphere" will be used here to include surface species which are sorbed by H-bonding with protonated surface hydroxyl groups or by hydrophobic interactions with adsorbed surfactant molecules. The adsorption of the ligand by formation of inner-sphere complexes between the ligand and structural iron at the oxide surface is usually considered to be the first step of a ligand-promoted dissolution mechanism [14]. This conclusion has been drawn based on observations of a linear correlation between the rate of ligand-promoted dissolution and the amount of adsorbed ligand, whereas the relationship between soluble ligand concentrations and dissolution rates has the same shape as the corresponding adsorption isotherm. This led to the formulation of a simple rate law:

$$
\mathrm{R}=\mathrm{k} \mathrm{L}_{\mathrm{ads}} .
$$

where the surface area normalized dissolution rate $\mathrm{R}$ [mol $\mathrm{s}^{-1} \mathrm{~m}^{-2}$ ] depends linearly on the adsorbed ligand concen-

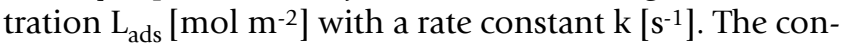
ceptual model underlying this rate law is based on the assumption that the formation of coordinative bonds between the inner-sphere adsorbing ligand and a surface metal center will kinetically labilize other bonds in the coordination sphere of the metal center and thereby promote the bond exchange reactions involved in its dissolution [14]. Indeed, the effect of inner sphere coordinating ligands on dissolution rates of simple oxides is well correlated to their effect on water exchange rates around corresponding metal centers in solution [15]. However, it is important to keep in mind that several surface sites and corresponding inner-sphere surface complexes with contrasting kinetic properties may exist [14]. Therefore, Equation 1 is only valid as long as this surface speciation is constant.

Studies on siderophore-promoted dissolution of iron oxides [13,16,17] and direct spectroscopic evidence [18] have suggested that siderophores can form inner-sphere surface complexes on iron oxide surfaces, in addition to possible outer-sphere complexes.

Surface-active agents (surfactants) are ubiquitous in natural systems $[19,20]$ and may potentially influence the free energy change of adsorption of siderophores [21]. Surfactants are structurally diverse organic compounds with amphiphilic properties arising from a hydrophobic hydrocarbon chain (tail) and hydrophilic (head) structural moieties in the same molecule [22]. The head groups can be anionic, cationic, non-ionic, or zwitterionic (i.e., bearing both positive and negative charge). Synthetic surfactants occur in the environment as contaminants due to their widespread use in industrial processes and as household detergents. In soils, bio-surfactants are produced by a range of microorganisms $[19,20]$ and their production can be triggered by nutrient limitations $[23,24]$. Root mucilage was also found to contain powerful bio-surfactants that affect biogeochemical and physical processes in the rhizosphere [25]. 
Adsorption of ionic surfactants on oppositely charged mineral surfaces has been the subject of intense research [26-30]. It is well accepted that anionic surfactant monomers adsorb on oppositely charged surfaces by electrostatic and specific forces at low surface coverage. With increasing surfactant concentrations, surfactant molecules form hemimicelles (monolayered clusters) or admicelles (bilayered clusters) on the surface by a combination of electrostatic and hydrophobic forces. With further increasing concentrations, adsorption eventually reaches a maximum at which mainly admicelles are present. This adsorption maximum is often reached near the $\mathrm{CMC}$, i.e., the surfactant concentration above which micelle formation occurs in solution. Surfactant adsorption on mineral surfaces changes the physico-chemical properties of the interface. For instance, at low concentrations, hemimicelles with surfactant heads close to the surface and tails directed toward the solution increase the hydrophobicity of the surface. Admicelles with a second layer of adsorbed surfactant with the head groups pointed toward the solution lead to surface charge reversal. As an example, the adsorption isotherm of the anionic surfactant sodium dodecyl sulfate (SDS) onto goethite has been presented in a previous paper [21].

The dramatic effects of adsorbed surfactants on surface charge and hydrophobicity may have important implications for the adsorption of siderophores and their iron complexes. In a previous study [21], we observed that the adsorption of DFOB to goethite increased with increasing concentrations of sodium dodecyl sulfate. Moreover, the presence of low surfactant concentrations in the low micromolar range caused a 3-fold acceleration of the dissolution rates of goethite.

The overall standard free energy change of adsorption of ions or molecules can be conceptually divided into various free energy contributions including free energy of chemisorption, electrostatic interactions, hydration and dipole-orientation, and hydrophobic interactions. In order to better understand the nature of the interactions responsible for siderophore adsorption in the presence of surfactants, we studied the influence of SDS on the adsorption of three complexing ligands and their respective iron complexes to goethite. We chose ligands with contrasting charge and hydrophobicity in order to explore how electrostatic and hydrophobic interactions with surfactants affect their adsorption. The dominant $\mathrm{H}_{2}$ EDTA $^{2-}$ species at $\mathrm{pH} 6$ is highly hydrophilic and negatively charged. The two siderophores contain a hydrophobic pentyl chain that is (at the experimental $\mathrm{pH}$ ) terminated by a positively charged amine group in the case of $\mathrm{DFOB}^{+}$. This group is acetylated and uncharged in the case of $\mathrm{DFOD}^{0}$, a synthetic derivate of DFOB (Figure 1a). In the following discussion, the charge of the main species will be indicated wherever relevant. Considering the structural distance of the modified terminal group to the hydroxamate groups of DFOB and DFOD, we assume that this modification has little effect on the properties of the ligating groups. This assumption is supported by the similarity of stability constants for their iron complexes in solution (see caption Figure 1) [7]. Therefore, the chemical interactions with surface sites (chemisorption) were expected to be similar for both siderophores. Consequently, we assume that any major differences in the effect of coadsorbed surfactants on DFOB and DFOD adsorption can be assigned to free energy contributions caused by electrostatic or hydrophobic interactions. The third ligand, EDTA (ethylenediaminetetra-acetic acid, Figure 1b), was chosen because of its negative charge and strong hydrophilicity [31]. All three ligands accelerate iron oxide dissolution by ligand-promoted dissolution mechanisms. Therefore, we also studied the adsorption of 1:1 iron-ligand complexes that are products of the dissolution process. SDS was chosen as a model for anionic surfactants occurring in soils. It should be noted that SDS does not capture the structural diversity of biosurfactants. However, SDS has been widely used in studies of the behavior of surfactants on mineral surfaces and provides a valuable basis for the understanding of their effect on ligand adsorption.

\section{Experimental methods Preparation of Goethite}

Goethite $(\alpha$-FeOOH) was synthesized following Böhm's method as described in Schwertmann and Cornell [32]. Briefly, $100 \mathrm{~mL}$ of freshly prepared $1 \mathrm{M} \mathrm{Fe}\left(\mathrm{NO}_{3}\right)_{3} \cdot 9 \mathrm{H}_{2} \mathrm{O}$ were mixed rapidly with $180 \mathrm{~mL}$ of $5 \mathrm{M} \mathrm{KOH}$ in a polypropylene beaker. All solutions used in this study were prepared with high-purity water (Milli-Q, Millipore, 18 $M \Omega \mathrm{cm}$ ). The precipitated hydrous ferric iron was immediately diluted to $2 \mathrm{~L}$ with deionized water and heated in closed polypropylene flasks at $70^{\circ} \mathrm{C}$ for 60 hours. Afterwards, the precipitate was resuspended in high-purity water, centrifuged, and decanted. This washing procedure was repeated several times until the supernatant was free of chloride and then freeze-dried. X-ray powder diffraction confirmed the formation of $\alpha$-FeOOH. The specific surface area was determined as $38 \mathrm{~m}^{2} \mathrm{~g}^{-1}$ by a multipoint $\mathrm{N}_{2}$-BET adsorption method (surface area analyzer Gemini 2360, Micromeritics, Belgium).

\section{Synthesis of desferrioxamine-D (DFOD)}

Prior to the synthesis of DFOD, N-acetyl-O,O,O-triacetyldesferrioxamin was synthesized as follows. DFOB (6.4 g, $10 \mathrm{mmol})$ and ground anhydrous $\mathrm{K}_{2} \mathrm{CO}_{3}(3 \mathrm{~g}, 20 \mathrm{mmol})$ were mixed with $\mathrm{H}_{2} \mathrm{O}$-free $\mathrm{N}$, N-dimethylformamide (25 $\mathrm{mL}$ ). This suspension was heated to $70^{\circ} \mathrm{C}$ under nitrogen atmosphere for $30 \mathrm{~min}$, then cooled to room temperature and diluted with $\mathrm{CH}_{2} \mathrm{Cl}_{2}(100 \mathrm{~mL})$. To this suspension, a solution of acetic anhydride $(4.1 \mathrm{~g}, 40 \mathrm{mmol})$ in $20 \mathrm{~mL}$ 
$\mathrm{CH}_{2} \mathrm{Cl}_{2}$ was slowly added over a period of $30 \mathrm{~min}$. The reaction mixture was stirred for $4 \mathrm{~h}$ and filtered. The filtrate was successively extracted with water $(2 \times 50 \mathrm{~mL})$, saturated aqueous $\mathrm{NaHCO}_{3}$ solution $(50 \mathrm{~mL})$ and aqueous sodium chloride solution $(50 \mathrm{~mL})$ and then dried over anhydrous $\mathrm{Na}_{2} \mathrm{SO}_{4}$. The solvents were removed in vacuo, and the $\mathrm{N}$-acetyl-O,O,O-triacetyl-desferrioxamine was obtained as colorless thick oil (yield $6.7 \mathrm{~g}, 9.2 \mathrm{mmol}$, which correspond to $92 \%$ of the theoretical obtainable amount). Then, the $\mathrm{N}$-acetyl-O,O,O-triacetyl-desferrioxamine was dissolved in $100 \mathrm{~mL}$ of methanol, cooled to $0{ }^{\circ} \mathrm{C}$ with an ice bath, and the solution was saturated with gaseous ammonia. The solution was kept at room temperature for $4 \mathrm{~h}$, and then refrigerated overnight. Crude DFOD was collected by filtration and re-crystallized twice from methanol/water for purification. Pure DFOD was obtained as colorless crystalline material. $4.8 \mathrm{~g}$ of DFOD were obtained corresponding to $84.7 \%$ of the theoretical obtainable amount. The melting point was $180 \pm 1{ }^{\circ} \mathrm{C}$. The relative composition of elements for $\mathrm{C}_{27} \mathrm{H}_{50} \mathrm{~N}_{6} \mathrm{O}_{9}$ was found to be: C, 53.93 (53.84); H, 8.44 (8.32); N, 13.76 $(13.95) \%$ (theoretical values are given in parenthesis). Detailed information on the characterization of DFOD is provided in additional file 1.

\section{Adsorption of free ligands in the presence of SDS}

The adsorption of EDTA (Fluka, Switzerland) and the siderophore DFOD to goethite as a function of increasing SDS (Fluka, Switzerland) concentrations was studied at pH 6 in $40 \mathrm{~mL}$ batch reactors. SDS concentrations were kept well below the critical micelle concentration $(\mathrm{CMC}=$ $3.1 \mathrm{mM}$ at $25^{\circ} \mathrm{C}$ in $0.01 \mathrm{M} \mathrm{NaCl}$; [33]). $30 \mathrm{~mL}$ batches of goethite $(\alpha-\mathrm{FeOOH})$ suspensions (solids concentrations of $7 \mathrm{~g} / \mathrm{L} ; \mathrm{pH} 6.0 \pm 0.05 ; 0.01 \mathrm{M} \mathrm{NaClO}_{4}$ (as ionic strength buffer)) containing SDS at various concentrations were prepared and pre-equilibrated for 68 hours on an endover-end shaker at $25 \pm 1^{\circ} \mathrm{C}$. Then, $10 \mathrm{~mL}$ of stock solutions containing $320 \mu \mathrm{M}$ EDTA, or DFOD in $0.01 \mathrm{M}$ $\mathrm{NaClO}_{4}$ adjusted to pH $6.0 \pm 0.05$ were added to the suspensions. The total concentrations of EDTA, or DFOD were $80 \mu \mathrm{M}$ in all batches and the total SDS concentrations varied from 0 to $600 \mu \mathrm{M}$. The suspension $\mathrm{pH}$ was measured using a pH electrode (Metrohm, 6.0234.100) and readjusted, if necessary, to $\mathrm{pH} 6.0 \pm 0.05$ by small additions of $\mathrm{NaOH}$ or $\mathrm{HCl}$. All reactors were wrapped in aluminum foil to avoid photochemical reactions. After 24 hours equilibration time on an end-over-end shaker at 25 $\pm 1^{\circ} \mathrm{C}, 5 \mathrm{~mL}$ aliquots of each suspension were filtered through $0.025 \mu \mathrm{m}$ cellulose nitrate membranes using polycarbonate syringe filter holders $(25 \mathrm{~mm}$ diameter, Schleicher \& Schuell, Germany). The concentration of adsorbed ligands was determined indirectly by measuring the ligand concentration left in solution after filtration. DFOD was immediately analyzed after filtration with a UV-visible spectrophotometer (Cary 50 BIO, Varian, Aus- tralia) as an iron complex in the presence of an excess of $\mathrm{Fe}(\mathrm{III})$ at $432 \mathrm{~nm}$ as described in [34]. EDTA was also analyzed spectrophotometrically as iron complex following a procedure described by Bhattach et al. [35]. Blank experiments without goethite were performed to monitor any losses due to adsorption of the ligands to the vessel or filter, but no significant losses were observed. During the 24 h equilibration time after the siderophore addition, some ligand-promoted dissolution of goethite may have occurred. However, based on the low dissolution rates of goethite at pH 6 in the presence of EDTA [36] and siderophores [37], the expected dissolved iron concentrations are in the low micromolar range and are not expected to affect the results.

\section{Adsorption of Fe complexes in the presence of SDS}

Stock solutions of 1:1 Fe-EDTA, Fe-DFOB and Fe-DFOD complexes $\left(120 \mu \mathrm{M}\right.$ in $\left.0.01 \mathrm{M} \mathrm{NaClO}_{4}\right)$ were prepared by dissolving $\mathrm{Fe}\left(\mathrm{NO}_{3}\right)_{3} \cdot 9 \mathrm{H}_{2} \mathrm{O}$ (Fluka, Switzerland) in a 0.01 $\mathrm{M} \mathrm{NaClO}_{4}$ solution and adding EDTA, DFOB, or DFOD solutions at equimolar concentrations. The stock solutions were added to goethite suspensions pre-equilibrated with SDS at pH $6.0 \pm 0.05$ at $25 \pm 1^{\circ} \mathrm{C}$. The suspension $\mathrm{pH}$ was measured and readjusted if necessary to $6.0 \pm 0.05$ by small additions of $\mathrm{NaOH}$ or $\mathrm{HCl}$. The experimental set up was similar to the adsorption experiments with free ligands as described above, except that the solids concentration was $2.5 \mathrm{~g} / \mathrm{L}$. The total concentration of Fe complexes in all reactors was $30 \mu \mathrm{M}$ and the total SDS concentration was $0-600 \mu \mathrm{M}$. The equilibration time after the addition of the Fe complexes was $24 \mathrm{~h}$. After filtration, the dissolved concentrations of iron complexes left in solution were immediately analyzed by inductively coupled plasma optical emission spectrometry (ICP-OES, VistaMPX, CCD Simultaneous, Varian, Australia) at the wavelength $238.2 \mathrm{~nm}$. In some experiments, the concentrations of 1:1 Fe complexes were also analyzed by UVvisible spectrophotometry. The lack of difference between these two methods indicated the formation of 1:1 Fe-ligand complexes (see additional file 2). In addition, $\mathrm{Fe}$ DFOB adsorption isotherms were recorded using a similar set-up in the presence of 0,15 , and $800 \mu \mathrm{M}$ total SDS, respectively. Samples were taken 24 hours after the addition of the iron complex, filtered, and iron concentrations were analyzed by ICP-OES.

\section{Results and discussion Adsorption of free ligands}

The influence of increasing SDS concentrations on the adsorption of EDTA and the siderophores DFOB (data from [21]) and DFOD is shown in Figure 2. SDS had almost no effect on the adsorption of EDTA, except for a slight decrease of EDTA adsorption at the highest SDS concentration $(600 \mu \mathrm{M})$. Considering the hydrophilic nature of EDTA, hydrophobic interactions with co- 


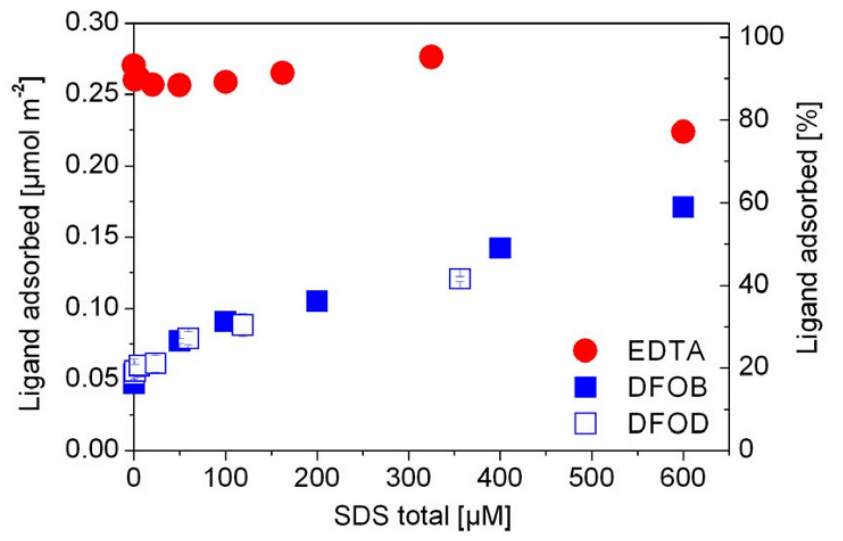

Figure 2

Adsorption of EDTA and the siderophores DFOB (data from [2I]) and DFOD onto goethite at pH 6 as a function of SDS concentration (0.0 I $\mathrm{M} \mathrm{NaClO}_{4}, 7 \mathrm{~g} /$ L goethite, $24 \mathrm{~h}$ equilibration time). The total ligand concentration was $80 \mu \mathrm{M}$. Error bars indicate the standard deviation of three replicates.

adsorbed SDS are not expected. The doubly deprotonated $\mathrm{H}_{2}$ EDTA $^{2-}\left(\mathrm{pK}_{\mathrm{a} 3}=6.13\right)$ is the dominant species in solution in the absence of soluble iron at $\mathrm{pH} 6$. Based on sorption and titration experiments combined with surface complexation modeling, Nowack and Sigg [38] proposed that the dominant surface species of EDTA at pH 6 is a triply deprotonated, singly charged binuclear inner-sphere surface complex ( $\equiv \mathrm{Fe}_{2}$ EDTA- $\left.^{-}\right)$

ATR-FTIR studies have conclusively shown that sulfate forms inner-sphere and outer-sphere surface complexes on goethite, depending on solution $\mathrm{pH}$ [39] At pH 6 and above, the dominant surface species was an outer-sphere surface complex, while at low pH sulfate was sorbed mainly as inner-sphere complex. Therefore, it seems likely that the sulfate head groups of SDS will also mainly form outer-sphere complexes at pH 6 . Hence, little adsorption competition between SDS and EDTA is expected at low surfactant concentrations. Indeed, SDS had little effect on EDTA sorption at concentrations $<600 \mu \mathrm{M}$ total SDS (Figure 2). Nevertheless, it is possible that adsorbed SDS forms a minor inner-sphere surface species via the sulfate head groups that may compete with EDTA for surface sites at the highest SDS concentration leading to the observed decrease of EDTA adsorption (Figure 2).

One could also assume that SDS may influence EDTA adsorption by modifying the charge at the mineral-water interface. Electrophoretic mobility measurements showed a reversal from positive to negative values upon formation of a surfactant bilayer on goethite [21]. However, electrophoretic mobility measurements probe the electrical potential at the plane of shear, which is beyond the sur- factant (bi)layer, i.e., at greater distance from the mineral surface. Under the assumption that EDTA forms only inner-sphere complexes and that the charge of adsorbed EDTA is located at or close to the surface its adsorption does not depend on variations of the potential above the hemimicelles and admicelles.

The surface potential depends, among other factors, on the protonation state of the surface and it has been observed that the adsorption of surfactants, especially at low concentrations, increases the protonation of oxide surfaces [40,41]. However, Nowack and Sigg [38] have reported that the adsorption of EDTA as a binuclear complex on goethite is constant between pH 5 and 7, which is consistent with our observation that possible SDSinduced changes of the surface protonation state at $\mathrm{pH} 6$ were small enough not to influence the adsorption of EDTA. Considering Equation 1, the observation of constant EDTA adsorption at variable SDS concentrations suggests that SDS should have no effect on EDTA promoted dissolution rates. However, SDS may affect the formation of inner-sphere surface complexes, and hence, the surface speciation of sorbed EDTA, which may potentially affect dissolution rates (vide supra).

While adsorbed SDS had little influence on EDTA adsorption, a strong effect on DFOB and DFOD adsorption was observed (Figure 2). The adsorption of DFOB and DFOD increased strongly with increasing SDS concentrations. Despite their difference in molecular charge, the effects of the anionic surfactant on the adsorption of $\mathrm{DFOB}^{+}$and DFOD $^{0}$ were similar.

Cocozza et al. [16] found that DFOB and DFOD form mononuclear inner-sphere surface complexes with a single hydroxamate group coordinating with a surface site. The adsorption of DFOD involves no net change of surface charge in analogy to the adsorption of the monohydroxamate ligand acetohydroxamic acid [17]. The adsorption of DFOB involves the increase of the surface charge due to the positive amine group, probably located relatively far from the goethite surface due to repulsive forces. The difference in charge of these two surface complexes should result in differences in the electrostatic interactions, which is consistent with the observation of somewhat higher adsorption densities of DFOD in the absence of surfactants under otherwise identical conditions [34].

The structures of the siderophores (Figure 1) include a pendant alkyl chain with five carbons giving rise to a local hydrophobic character of the molecule. Bonilha et al. [42] observed that the exchange constant between $\mathrm{Na}^{+}$and alkylammonium ions ( $\mathrm{R}-\mathrm{NH}_{3}{ }^{+}$, with $\mathrm{R}=\mathrm{C}_{\mathrm{n}} \mathrm{H}_{2 \mathrm{n}+1}$ ) in SDS micelles increases with increasing chain size, indicating 
that hydrophobic interactions contribute to the enhanced exchange constants. Therefore, increased siderophore adsorption in the presence of co-adsorbed SDS suggests that hydrophobic interactions between ligands and surfactants are responsible for the observed behavior. The observed effect of SDS on the adsorption of the two siderophores was similar despite their difference in molecular charge. These observations imply that coadsorbed surfactants have little influence on electrostatic free energy contributions to siderophore adsorption. This is consistent with our interpretation of the absence of an effect of surfactants on EDTA adsorption as discussed above.

\section{Adsorption of $\mathrm{Fe}(\mathrm{III})$-complexes}

Adsorption of 1:1 $\mathrm{Fe}(\mathrm{III})$-complexes was quantified by measuring the loss of Fe-complexes from solution by UV spectrophotometry and the loss of total Fe by ICP-OES. Both methods gave identical results (see additional file 2), confirming the adsorption of 1:1 Fe-ligand complex. Adsorption equilibrium of $\mathrm{Fe}$-DFOB on goethite was reached after $24 \mathrm{~h}$ (see additional file 2). SDS had strong effects on the adsorption of the complexes of DFOB, DFOD, and EDTA (Figure 3a).

The adsorption of the Fe-EDTA complex decreased by almost $75 \%$ at the highest SDS concentration relative to adsorption in the absence of SDS. The adsorption behavior of free ligands compared to their iron complexes in the presence of surfactants can be interpreted in terms of their different adsorption modes. In solution, the dominant $\mathrm{Fe}$ EDTA complex is a quinquedentate seven-coordinated bisaquo $\mathrm{Fe}(\mathrm{III}) \mathrm{EDTA}^{-} \cdot\left(\mathrm{H}_{2} \mathrm{O}\right)_{2}$ with a free carboxylic group [43,44]. Nowack and Sigg [38] suggested that the dominant surface complex at $\mathrm{pH}$ values below 7 is an outer-sphere complex $\left(\equiv \mathrm{FeOH}_{2}{ }^{+} \cdot \mathrm{LFe}-\right)$, while an innersphere complex was postulated to dominate at higher $\mathrm{pH}$ values $\left(\equiv \mathrm{FeOFeL}^{2-}\right)$. Therefore, the contrasting effect of SDS on the adsorption of EDTA and its iron complex at pH 6 can be interpreted in terms of their adsorption as inner-sphere and outer-sphere complex, respectively. While the adsorption of the Fe-EDTA complex decreased with increasing SDS concentration (Figure 3a), coadsorbed surfactants had little effect on free EDTA adsorption (Figure 2). As discussed above, the charge of surfactant aggregates on the goethite surface appeared to have little effect on electrostatic contributions to EDTA adsorption. On the contrary, the Fe-EDTA outer-sphere complex is adsorbed mainly by electrostatic interactions and its plane of adsorption can be expected at greater distance from the mineral surface. Therefore, decreasing adsorption of the negatively charged Fe-EDTA outersphere complex with increasing SDS adsorption suggests that electrostatic repulsion between admicelles and the iron complex decrease its adsorption. Nevertheless, some (a)
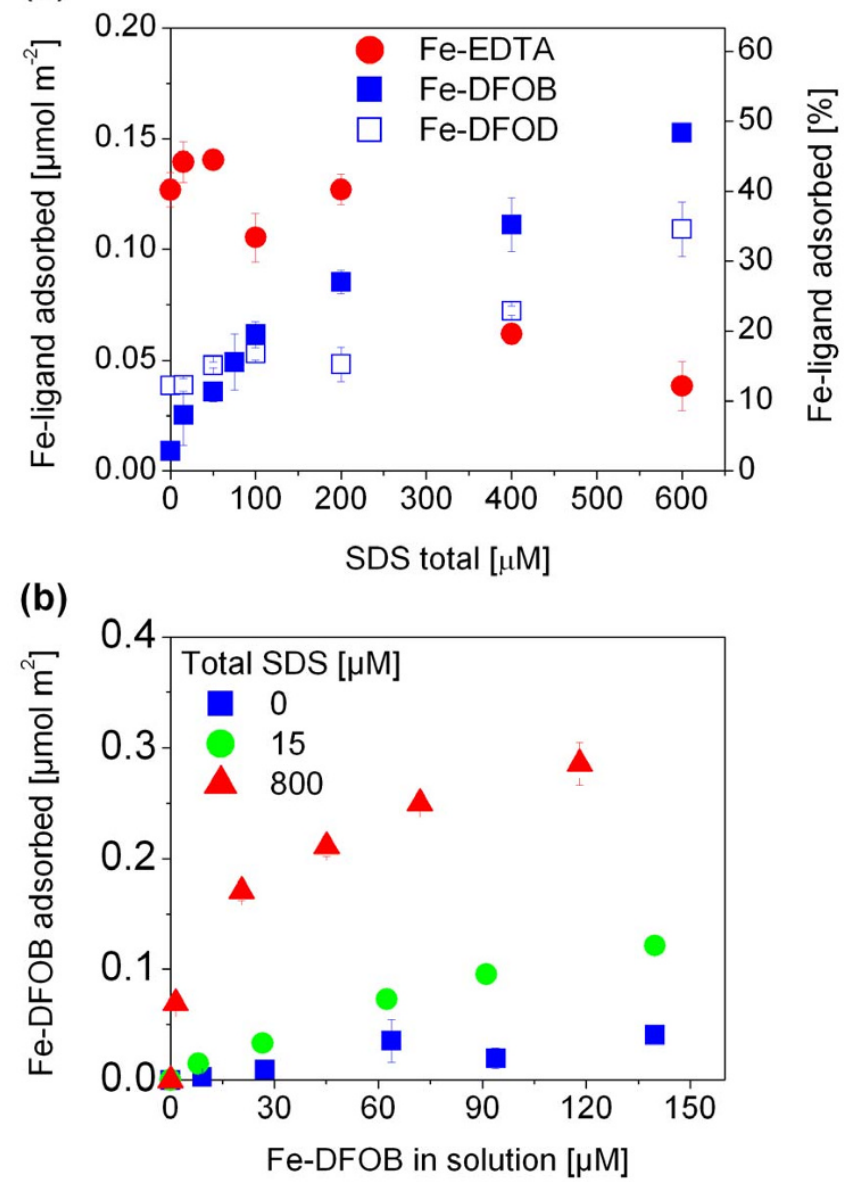

Figure 3

(a) Adsorption of Fe-EDTA, Fe-DFOB, and Fe-DFOD complexes on goethite at $\mathrm{pH} 6$ as a function of SDS concentration. The total concentration of Fe-ligand complexes was $30 \mu \mathrm{M}$. (b) Adsorption isotherm of Fe-DFOB to goethite at $\mathrm{pH} 6$ in the presence of $0,15,800 \mu \mathrm{M}$ total SDS. For (a) and (b) $0.01 \mathrm{M} \mathrm{NaClO}_{4}, 2.5 \mathrm{~g} / \mathrm{L}$ goethite, $24 \mathrm{~h}$ equilibration time. Error bars indicate the standard deviation of three replicates.

adsorption still occurred at SDS concentrations where electrophoretic mobility measurements indicated charge reversal [21]. This behavior is consistent with the formation of inner-sphere surface complexes (Equation 4) as a minor surface species [38].

In contrast, the adsorption of Fe-DFOB and Fe-DFOD increased over the same range of surfactant concentrations (Figure 3a). The adsorption of Fe-DFOD was higher than that of Fe-DFOB at low surfactant concentrations. At high SDS concentrations, higher adsorption of Fe-DFOB than that of Fe-DFOD was observed. Figure $3 \mathrm{~b}$ shows the influence of low and high SDS concentrations on the adsorption isotherms of Fe-DFOB on goethite at $\mathrm{pH}$ 6. Again, 
Table I: Adsorbed amounts of SDS and DFOB on goethite (SDS ads $_{\text {, DFOB }}$ ads) as influenced by the total SDS concentration (SDS tot in suspension at pH 6.

\begin{tabular}{|c|c|c|c|c|c|}
\hline $\mathrm{SDS}_{\text {tot }}$ & $\mathrm{SDS}_{\mathrm{ads}}$ & $\Delta\left(\mathrm{SDS}_{\mathrm{ads}}\right)$ & $\mathrm{DFOB}_{\text {ads }}$ & $\Delta\left(\right.$ DFOB $\left._{\text {ads }}\right)$ & $\Delta\left(\mathrm{DFOB}_{\mathrm{ads}}\right) / \Delta\left(\mathrm{SDS}_{\mathrm{ads}}\right)$ \\
\hline 0 & 0.000 & --- & 0.047 & --- & --- \\
\hline 50 & 0.054 & 0.054 & 0.077 & 0.030 & 0.56 \\
\hline 100 & 0.107 & 0.054 & 0.091 & 0.014 & 0.25 \\
\hline 200 & 0.214 & 0.107 & 0.105 & 0.014 & 0.13 \\
\hline 400 & 0.439 & 0.224 & 0.142 & 0.037 & 0.17 \\
\hline 600 & 0.781 & 0.342 & 0.171 & 0.029 & 0.08 \\
\hline
\end{tabular}

The goethite concentration was $7 \mathrm{~g} / \mathrm{L}$ and the total DFOB concentration was $80 \mu \mathrm{M}$.

The SDS adsorption data were taken from [2I] and were measured in the absence of DFOB. $\Delta\left(\right.$ SDS $\left._{\mathrm{ads}}\right)$ and $\Delta\left(\mathrm{DFOB}_{\mathrm{ads}}\right)$ denote the additional SDS and DFOB adsorbed relative to the next lower $S_{\text {tot }}$ concentration. The ratio $\Delta\left(\right.$ DFOB $\left._{\text {ads }}\right) / \Delta\left(\mathrm{SDS}_{\text {ads }}\right)$ is an estimate for the additional amount of DFOB adsorbed due to additional adsorption of SDS to the goethite surface.

increasing surface concentrations of the Fe-DFOB complex were observed with increasing surfactant concentration. Over a wide $\mathrm{pH}$ range $(\mathrm{pH} 2-11)$, including the experimental $\mathrm{pH}$ of this study, the charge of the iron complexes of the siderophores $\mathrm{Fe}-\mathrm{DFOB}+$ and $\mathrm{Fe}-\mathrm{DFOD}^{0}$ is the same as the charge of free siderophores [45]. The formation of 6 five-membered rings completely satisfies the coordinative requirements of $\mathrm{Fe}(\mathrm{III})$ resulting in extremely stable complexes. Therefore, it is unlikely that the chelated iron adsorbs as inner-sphere surface complex and $\mathrm{Fe}-\mathrm{DFOB}^{+}$and $\mathrm{Fe}-\mathrm{DFOD}^{0}$ are expected to interact with the surfactant-coated goethite surface by electrostatic or hydrophobic interactions as outer-sphere surface complexes. Increasing adsorption of both complexes with increasing surfactant concentrations again underlines the importance of the hydrophobic interactions between the hydrophobic backbone of siderophores and the surfactant tail. However, the effect of hemimicelle/admicelle formation on $\mathrm{Fe}-\mathrm{DFOB}^{+}$adsorption was stronger than the effect on $\mathrm{Fe}-\mathrm{DFOD}^{0}$ adsorption (higher adsorption of $\mathrm{Fe}$ $\mathrm{DFOB}^{+}$, Figure 3a). In contrast to the neutral Fe-DFOD ${ }^{0}$, the adsorption of $\mathrm{Fe}-\mathrm{DFOB}^{+}$benefits not only from hydrophobic interactions but also from electrostatic interactions with the negatively charged admicelle. The positively charged $\mathrm{Fe}-\mathrm{DFOB}^{+}$experiences electrostatic repulsion resulting in low surface concentrations compared to Fe-DFOD ${ }^{0}$ at small surfactant concentrations. At higher surfactant concentrations $(<100 \mu \mathrm{M}$ total SDS $)$, Fe-DFOB ${ }^{+}$experiences attractive forces due to charge reversal (see electrophoretic mobility in [21]) caused by the formation of hemimicelle and admicelle and its adsorption exceeded Fe-DFOD ${ }^{0}$ adsorption. This electrostatic effect is not seen in the adsorption of free siderophores forming mainly inner sphere complexes resulting in the location of the charge of the surface complex closer to the mineral surface as discussed above.

Table 1 provides the adsorbed concentrations of SDS and DFOB to goethite at $\mathrm{pH} 6$ as influenced by total SDS con- centration in suspension. The ratio $\left.\Delta\left(\mathrm{DFOB}_{\mathrm{ads}}\right) / \Delta \mathrm{SDS}_{\mathrm{ads}}\right)$ indicates how much additional DFOB was adsorbed with additional adsorption of SDS. These values are only rough estimates, because they are based on SDS adsorption data determined in the absence of the siderophore [21], which was found to have a minor effect on SDS adsorption in preliminary experiments. The strong decrease of the ratio $\Delta\left(\mathrm{DFOB}_{\mathrm{ads}}\right) / \Delta\left(\mathrm{SDS}_{\mathrm{ads}}\right)$ with increasing SDS concentration suggests that the effect of adsorbed SDS on the adsorption of DFOB was largest at low SDS surface coverage. Similar differences in ratios were observed for the co-adsorption of fluorocarbon alcohols [46] and 1-pentanol [47] in the presence of adsorbed surfactants on mineral surfaces. These alcohols possess hydrophobic and charged structural moieties that contribute to electrostatic and hydrophobic interactions with adsorbed surfactants, in analogy to the mechanism of siderophore adsorption discussed above. Lai et al. [46] and Lee et al. [47] suggested that low amounts of adsorbed surfactant create two different regions to which amphiphilic compounds can co-adsorb. One region is located between the head groups of the surfactants, and the second region is the hydrophobic perimeter arising from patchwise adsorption of bilayered surfactant aggregates mainly present at low surfactant concentrations [47]. They suggested that the fraction of alcohol adsorbed at the perimeter can be large only at low surfactant concentrations when the aggregates are small and sparse on the mineral surface. Similarly, Asvapathanagul et al. [48], suggested that the structure, nature, or arrangement of adsorbed surfactants at low concentrations had a much stronger effect on co-adsorption of solutes than the actual adsorbed amount. The high $\Delta\left(\mathrm{DFOB}_{\mathrm{ads}}\right) / \Delta\left(\mathrm{SDS}_{\mathrm{ads}}\right)$ ratios observed at low SDS loadings suggest that DFOB adsorbs in the two different regions mentioned above.

\section{Conclusion}

Our results demonstrate that adsorbed surfactants can have a strong influence on the adsorption of siderophores 
and other ligands, as well as the corresponding iron complexes. The degree by which ligand adsorption is impacted by co-adsorbed surfactants depends on their charge, hydrophobicity, and on whether they are adsorbed as outer-sphere or inner-sphere surface complexes. Adsorption of ligands and their Fe-complexes by hemimicelles through hydrophobic and/or electrostatic interactions with the surfactants (here considered as a special case of outer-sphere adsorption) can dramatically change the surface speciation. The altered adsorption of ligands in the presence of surfactants can affect surface controlled processes such as ligand-promoted iron oxide dissolution and the bioavailability of iron. This effect is possibly of high importance not only in soil systems, but also in marine systems where amphiphilic siderophores have been observed [3]. Therefore, the effect of adsorbed surfactants on surface controlled processes can not be neglected in natural environments, where ligands and bio-surfactants are often produced and released together by microorganisms and plants roots.

\section{Competing interests}

The authors declare that they have no competing interests.

\section{Authors' contributions}

NC conducted the adsorption experiments and wrote the first version of the manuscript as part of her PhD thesis, JX synthesized and characterized the DFOD, and SK and RK initiated and supervised the study, and were involved in planning experiments, interpreting data, and revising the manuscript for publication. All authors have read and approved the final manuscript.

\section{Additional material}

\section{Additional file 1}

Additional details about the characterization of DFOB by NMR spectroscopy.

Click here for file

[http://www.biomedcentral.com/content/supplementary/14674866-10-5-S1.pdf]

\section{Additional file 2}

Figure showing the adsorption kinetics of $\mathrm{Fe}-\mathrm{DFOB}$ on goethite. Click here for file

[http://www.biomedcentral.com/content/supplementary/14674866-10-5-S2.pdf]

\section{Acknowledgements}

We are most grateful to Kurt Barmettler and Marie-Laure Pesch for their help in the laboratory, and Iso Christl, Jon Chorover and Luuk Koopal for providing useful comments on an earlier version of the manuscript. This research was financially supported by the Swiss National Science Foundation (SNF, Grants No. 66910 and I I2280).

\section{References}

I. Neilands JB: Some aspects of microbial iron metabolism. Bacteriol Rev 1957, 21:101-III.

2. Albrecht-Gary AM, Crumbliss AL: Coordination chemistry of siderophores. Thermodynamics and kinetics of iron chelation and release. In Metal lons in Biological Systems Edited by: Sigel A, Sigel H. New York: Marcel Dekker, Inc; 1998:239-327.

3. Kraemer SM, Butler A, Borer P, Cervini-Silva J: Siderophores and the dissolution of iron bearing minerals in marine systems. Rev Mineral Geochem 2005, 59:53-76.

4. Kraemer SM, Crowley D, Kretzschmar R: Siderophores in plant iron acquisition: Geochemical aspects. Adv Agron 2006, 9 I: I-46.

5. Matzanke BF, Muller-Matzanke G, Raymond KN: Siderophores mediated iron transport. In Iron Carriers and Proteins Edited by: Loehr TM. New York: VCH Publisher; 1989:I-I2I.

6. Boukhalfa $\mathrm{H}$, Crumbliss $\mathrm{AL}$ : Chemical aspects of siderophore mediated iron transport. Biometals 2002, 15:325-339.

7. Martell AE, Smith RM, Motekaitis RJ: NIST Critically Selected Stability Constants of Metal Complexes Database Gaithersburg MD: NIST; 200I.

8. Murakami T, Ise K, Hayakawa M, Kamei S, Takagi SI: Stabilities of metal-complexes of mugineic acids and their specific affinities for iron(III). Chem Letters 1989:2 I37-2 I40.

9. Winkelmann G: Specificity of iron transport in bacteria and fungi. In CRC Handbook of Microbial Iron Chelates Edited by: Winkelmann G. Boca Raton: CRC Press; 1991:65-106.

10. Kalinowski BE, Liermann LJ, Givens S, Brantley SL: Rates of bacteria-promoted solubilization of $\mathrm{Fe}$ from minerals: a review of problems and approaches. Chem Geol 2000, 169:357-370.

11. Borgias B, Hugi AD, Raymond KN: Isomerization and solution structures of desferrioxamine-B complexes of $\mathrm{Al}^{3+}$ and $\mathrm{Ga}^{3+}$. Inorg Chem 1989, 28:3538-3545.

12. Powell PE, Cline GR, Reid CPP, Szaniszlo PJ: Occurrence of hydroxamate siderophores iron chelators in soils. Nature 1980, 287:833-834.

13. Kraemer SM: Iron oxide dissolution and solubility in the presence of siderophores. Aquat Sci 2004, 66:3-18.

14. Furrer $\mathrm{G}$, Stumm W: The coordination chemistry of weathering. I. Dissolution kinetics of $\delta-\mathbf{A l}_{2} \mathbf{O}_{3}$ and $\mathbf{B e O}$. Geochim Cosmochim Acta 1986, 50: 1847-I860.

15. Ludwig C, Casey WH, Rock PA: Prediction of ligand-promoted dissolution rates from the reactivities of aqueous complexes. Nature 1995, 375:44-47.

16. Cocozza C, Tsao CCG, Cheah SF, Kraemer SM, Raymond KN, Miano TM, Sposito G: Temperature dependence of goethite dissolution promoted by trihydroxamate siderophores. Geochim Cosmochim Acta 2002, 66:43।-438.

17. Holmén $\mathrm{BA}$, Casey $\mathrm{WH}$ : Hydroxamate ligands, surface chemistry, and the mechanism of ligand-promoted dissolution of goethite $[\alpha-\mathrm{FeOOH}(\mathbf{s})]$. Geochim Cosmochim Acta 1996, 60:4403-4416.

18. Yang J, Bremer PJ, Lamont IL, McQuillan AJ: Infrared spectroscopic studies of siderophore-related hydroxamic acid ligands adsorbed on titanium dioxide. Langmuir 2006, 22:10109-10117.

19. Rosenberg E, Ron EZ: High- and low-molecular-mass microbial surfactants. Appl Microbiol Biotechnol 1999, 52:154-162.

20. Bodour AA, Drees KP, Maier RM: Distribution of biosurfactantproducing bacteria in undisturbed and contaminated arid southwestern soils. Appl Environ Microbiol 2003, 69:3280-3287.

21. Carrasco N, Kretzschmar R, Pesch M-L, Kraemer SM: Low concentrations of surfactants enhance siderophore-promoted dissolution of goethite. Environ Sci Technol. 2007, 4 I (10):3633-3638.

22. Attwood D, Florence A: Surfactants System. Their Chemistry, Pharmacy, and Biology New York: Chapman and Hall; 1983.

23. Hudak AJ, Cassidy DP: Stimulating in-soil rhamnolipid production in a bioslurry reactor by limiting nitrogen. Biotechnol Bioeng 2004, 88:86I-868.

24. Guerrasantos L, Kappeli O, Fiechter A: Pseudomonas-aeruginosa biosurfactant production in continuous culture with glucose as carbon source. Appl Environ Microbiol 1984, 48:30I-305.

25. Read DB, Bengough AG, Gregory PJ, Crawford JW, Robinson D, Scrimgeour CM, Young IM, Zhang K, Zhang X: Plant roots release phospholipid surfactants that modify the physical and chemical properties of soil. New Phytol 2003, 157:315-326.

26. Chandar P, Somasundaran P, Turro NJ: Fluorescence probe studies on the structure of the adsorbed layer of dodecyl-sulfate 
at the alumina-water interface. I Colloid Interface Sci 1987, I I 7:31-46.

27. Koopal LK, Lee EM, Böhmer MR: Adsorption of cationic and anionic surfactants on charged metal-oxide surfaces. J Colloid Interface Sci 1995, 170:85-97.

28. Fuerstenau DW, Colic M: Self-association and reverse hemimicelle formation at solid-water interfaces in dilute surfactant solutions. Colloids Surf A 1999, 146:33-47.

29. Scamehorn JF, Schechter RS, Wade WH: Adsorption of surfactants on mineral oxide surfaces from aqueous-solutions. I. Isomerically pure anionic surfactants. J Colloid Interface Sci 1982, 85:463-478.

30. Cases JM, Mielczarski J, Mielczarska E, Michot LJ, Villieras F, Thomas $F$ : lonic surfactants adsorption on heterogeneous surfaces. Comptes Rendus Geosci 2002, 334:675-688.

31. Boukhalfa H, Reilly SD, Smith WH, Neu MP: EDTA and mixed-ligand complexes of tetravalent and trivalent plutonium. Inorg Chem 2004, 43:5816-5823.

32. Schwertmann U, Cornell RM: Iron Oxides in the Laboratory. Preparation and Characterization 2nd edition. Weinheim: Wiley- $\mathrm{VCH} ; 2000$

33. Mukerjee Pasupati MKJ: Critical Micelle Concentration of Aqueous Surfactant Systems Washington, DC: National Standard Reference Data System; 197I.

34. Kraemer SM, Cheah SF, Zapf R, Xu JD, Raymond KN, Sposito G Effect of hydroxamate siderophores on Fe release and $\mathrm{Pb}$ (II) adsorption by goethite. Geochim Cosmochim Acta 1999 , 63:3003-3008.

35. Bhattach SN, Kundu KP: Spectrophotometric determination of EDTA. Talanta | 971, 18:446-449.

36. Nowack B, Lutzenkirchen T, Behra P, Sigg L: Modeling the adsorption of metal-EDTA complexes onto oxides. Env Sci Technol 1996, 30:2397-2405.

37. Reichard PU, Kretzschmar R, Kraemer SM: Dissolution mechanisms of goethite in the presence of siderophores and organic acids. Geochim Cosmochim Acta 2007, 71:5635-5650.

38. Nowack B, Sigg L: Adsorption of EDTA and metal-EDTA complexes onto goethite. J Colloid Interface Sci 1996, I77:106-12I.

39. Peak D, Ford RG, Sparks DL: An in situ ATR-FTIR investigation of sulfate bonding mechanisms on goethite. J Colloid Interface Sci 1999, 21 8:289-299.

40. Goloub TP, Koopal LK, Bijsterbosch BH, Sidorova MP: Adsorption of cationic surfactants on silica. Surface charge effects. Langmuir 1996, I 2:3 |88-3194.

4I. Böhmer MR, Koopal LK: Adsorption of ionic surfactants on variable-charge surfaces. I. Charge effects and structure of the adsorbed layer. Langmuir 1992, 8:2649-2659.

42. Bonilha JBS, Mary R, Georgetto Z, Abuin E, Lissi E, Quina F: Exchange between alkylammonium and sodium-ions at the surface of dodecyl-sulfate micelles. J Colloid Interface Sci 1990, 135:238-245.

43. Nuttall RH, Stalker DM: Structure and bonding in metal-complexes of ethylenediaminetetra-acetic acid. Talanta 1977, 24:355-360.

44. Hoard JL, Smith GS, Kennard CHL: Stereochemistry of ethylenediaminetetraacetato complexes: chromium(III), iron(III), and gallium(III) complex acids. Inorg Chem 1963, 2:1316.

45. Kiss T, Farkas E: Metal-binding ability of desferrioxamine B. J Inclusion Phenom Molec Recogn Chem 1998, 32:385-403.

46. Lai $\mathrm{CL}$, Orear EA, Harwell $\mathrm{JH}, \mathrm{Hwa}$ MJ: Adsolubilization of fluorocarbon alcohols into perfluoroheptanoate admicelles formed on alumina. Langmuir 1997, I 3:4267-4272.

47. Lee C, Yeskie MA, Harwell JH, Orear EA: Two-site adsolubilization model of incorporation of alcohols into adsorbed surfactant aggregates. Langmuir 1990, 6: 1758-1762.

48. Asvapathanagul $P$, Malakul $P, O^{\prime}$ Haver J: Adsolubilization of toluene and acetophenone as a function of surfactant adsorption. J Colloid Interface Sci 2005, 292:305-3 | I.
Publish with Bio Med Central and every scientist can read your work free of charge

"BioMed Central will be the most significant development for disseminating the results of biomedical research in our lifetime. "

Sir Paul Nurse, Cancer Research UK

Your research papers will be:

- available free of charge to the entire biomedical community

- peer reviewed and published immediately upon acceptance

- cited in PubMed and archived on PubMed Central

- yours - you keep the copyright
BioMedcentral 